\title{
Microstructure and Stress-Rupture Property of Large-Scale Complex Nickel-Based Single Crystal Casting
}

\author{
Min Huang ${ }^{1,2} \cdot$ Gong Zhang ${ }^{1} \cdot$ Dong Wang $^{1} \cdot$ Jia-Sheng Dong ${ }^{1} \cdot$ Li Wang $^{1} \cdot$ Lang-Hong Lou $^{1}$
}

Received: 13 October 2017 / Revised: 27 December 2017/Published online: 26 February 2018

(C) The Chinese Society for Metals and Springer-Verlag GmbH Germany, part of Springer Nature 2018

\begin{abstract}
The microstructure and stress-rupture property of the large-scale complex single crystal (SX) casting DD10 were investigated in high-rate solidification process. It is found that the primary dendrite arm spacing (PDAS) does not increase monotonically with the height increase. When across the platform, the temperature gradient increases due to the effect of platform, and the corresponding PDAS decreases. The distribution of eutectic volume fraction in large-scale complex SX casting is affected by PDAS, solid back diffusion, and the development of high order dendrites. The eutectic volume fraction contained in the sample taken below the platform decreases with the height increase. While the eutectic volume fraction contained in the sample taken upper the platform increases gradually with the height increase. After heat treatment, most of the $\gamma / \gamma^{\prime}$ eutectics are eliminated and the components are distributed uniformly. The similar stress rupture properties of the samples at different heights in the same direction are obtained.
\end{abstract}

Keywords Large-scale single crystal · Platform · Primary dendrite arm spacing · Eutectic volume fraction . Stress-rupture property

\section{Introduction}

Nickel-based single crystal (SX) superalloys have been widely used in aero-engines and gas turbines due to the excellent high-temperature mechanical properties. To obtain higher turbine entry temperature, and, therefore, to increase the efficiency of engines and turbines, the properties of superalloys need to be further improved. One of the important high-temperature properties is stress-rupture property [1]. In long-term service of turbine components, it is common that the microstructures degrade due to the interaction of elevated temperature and stress in the harsh working condition, which finally results in the stress rupture originating from the interdendritic region [2-4]. Therefore, it is necessary to investigate the microstructures

Available online at http://link.springer.com/journal/40195.

Gong Zhang

gzhang@imr.ac.cn

1 Institute of Metal Research, Chinese Academy of Sciences, Shenyang 110016, China

2 University of Chinese Academy of Sciences, Beijing 100049, China and the corresponding stress-rupture property of nickelbased SX superalloys, developing the application of superalloys in the fields of aero-engines and gas turbines further.

Usually, nickel-based SX superalloys are manufactured by high-rate solidification (HRS) process with Bridgman furnace $[5,6]$. Owing to the complex geometry shape of turbines, it is difficult to produce perfect SX castings by using HRS process, especially in large-scale industrial gas turbines. Serious segregation is easily formed during DS process, and the stress rupture properties may be deteriorated due to the occurrence of cast defects [7-10]. Relevant researches have been carried out to study the solidification of large-scale castings. Yu et al. [11, 12] compared the microstructures of large-scale turbine blade castings produced under different withdrawal rates. Jiang et al. [13, 14] and Zhang et al. [15] investigated the microstructures and stress rupture properties of large-scale directional column alloys. Few researchers have paid attention to the difference of the microstructures in different positions of largescale complex SX castings produced using HRS process. In addition, the stress rupture properties have been often characterized by measuring SX rods [16-22]. Compared with simple SX rods, the geometry shape of turbine blades 
produced by large-scale SX casting is complex. Therefore, it is necessary to study the microstructures and stress rupture properties of large-scale complex SX castings.

In this study, the microstructure and stress-rupture property of large-scale complex SX casting DD10 are analyzed in depth. The microstructures in the as-cast and heat-treated conditions in different positions of large-scale casting are characterized, and the effect of heat treatment on the stress-rupture property is discussed in detail. These results are expected to provide a reference for the industrial production of large-scale complex SX castings.

\section{Experimental}

The directional solidification (DS) experiment was carried out in a Bridgman high-rate solidification (HRS) industrial vacuum furnace. The first generation SX DD10 with a nominal composition shown in Table 1 was used in the present work. DD10 was cast into a large-scale SX casting with a platform, as shown in Fig. 1. The temperatures of holding furnace in the upper hot zone and the next lower zone were set as 1793 and $1823 \mathrm{~K}$, respectively. After heat preservation for thermal equilibrium, the mold was withdrawn at the rate of $3 \mathrm{~mm} / \mathrm{min}$.

To investigate the effect of heat treatment on the microstructures of DD10 large-scale SX casting with platform, five samples were cut at different heights from the bottom of the casting as marked in Fig. 1 (A: $44 \mathrm{~mm}$; B: $124 \mathrm{~mm}$; C: $154 \mathrm{~mm}$; D: $234 \mathrm{~mm}$; E: $314 \mathrm{~mm}$ ). These five samples were divided into two sections. Half was kept in the as-cast condition, and the other half and the remaining SX casting with platform were solution treated at $1533 \mathrm{~K}$ for $6 \mathrm{~h}$, precipitation treated at $1373 \mathrm{~K}$ for $4 \mathrm{~h}$, and aged at $1143 \mathrm{~K}$ for $24 \mathrm{~h}$.

The microstructures of the samples at different heights in the as-cast and heat-treated conditions were characterized by optical microscopy (OM). According to the microstructure, the primary dendrite arm spacing (PDAS) and the eutectic volume fraction were measured. The PDAS was calculated by the following equation:

$\lambda=(S / N)^{1 / 2}$,

where $S$ is the area of the metallurgical photo, and $N$ is the number of the dendrites. To ensure the accuracy, at least ten photos were acquired for calculation for each sample.

Table 1 Nominal chemical composition (wt\%) of experimental alloy DD10 in present work

\begin{tabular}{llllllll}
\hline $\mathrm{Cr}$ & $\mathrm{Co}$ & $\mathrm{Mo}$ & $\mathrm{W}$ & $\mathrm{Al}$ & $\mathrm{Ti}$ & $\mathrm{Ta}$ & $\mathrm{Ni}$ \\
\hline 12.5 & 4.0 & 0.2 & 5.0 & 3.6 & 4.0 & 5.0 & $\mathrm{Bal}$.
\end{tabular}

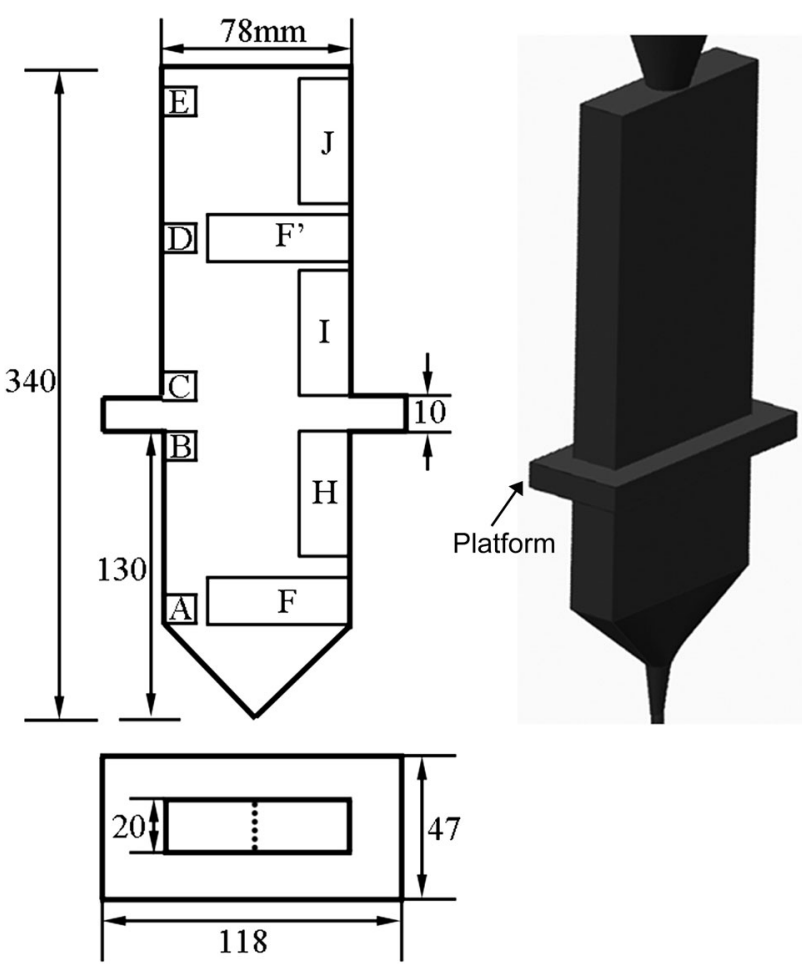

Fig. 1 Schematic diagram of large-scale single crystal casting with platform. A, B, C, D, and E represent the samples at different heights for microstructural analysis. F, F', H, I, and $\mathrm{J}$ are the samples taken for the stress rupture experiments.

The eutectic volume fraction, which represents the degree of element microsegregation, was obtained by an image analysis software (Image Pro Plus 6.0). At least fifteen metallurgical photos were analyzed to measure the eutectic volume fraction in each sample. In addition, the element segregation coefficients in the as-cast and heat-treated conditions were measured by electro-probe microanalyzer (EPMA).

The stress rupture experiments of DD10 in large-scale SX casting with platform after heat treatment were performed at $1253 \mathrm{~K}$ and $248 \mathrm{MPa}$. The samples (marked as $\mathrm{F}, \mathrm{F}^{\prime}, \mathrm{H}, \mathrm{I}, \mathrm{J}$ ) were cut from different positions as shown in Fig. 1. The fracture morphologies of ruptured samples were observed by scanning electron microscopy (SEM).

\section{Results}

Figure 2 shows the typical dendrite morphologies of the samples at different heights from the bottom of the casting (A-E marked in Fig. 1) with platform. According to the dendrite morphology, the PDAS is calculated and is shown in Fig. 2f. The PDAS increases with the height increase (from A to B) and decreases sharply when just across the platform (from $B$ to $C$ ), after then, it increases along the 

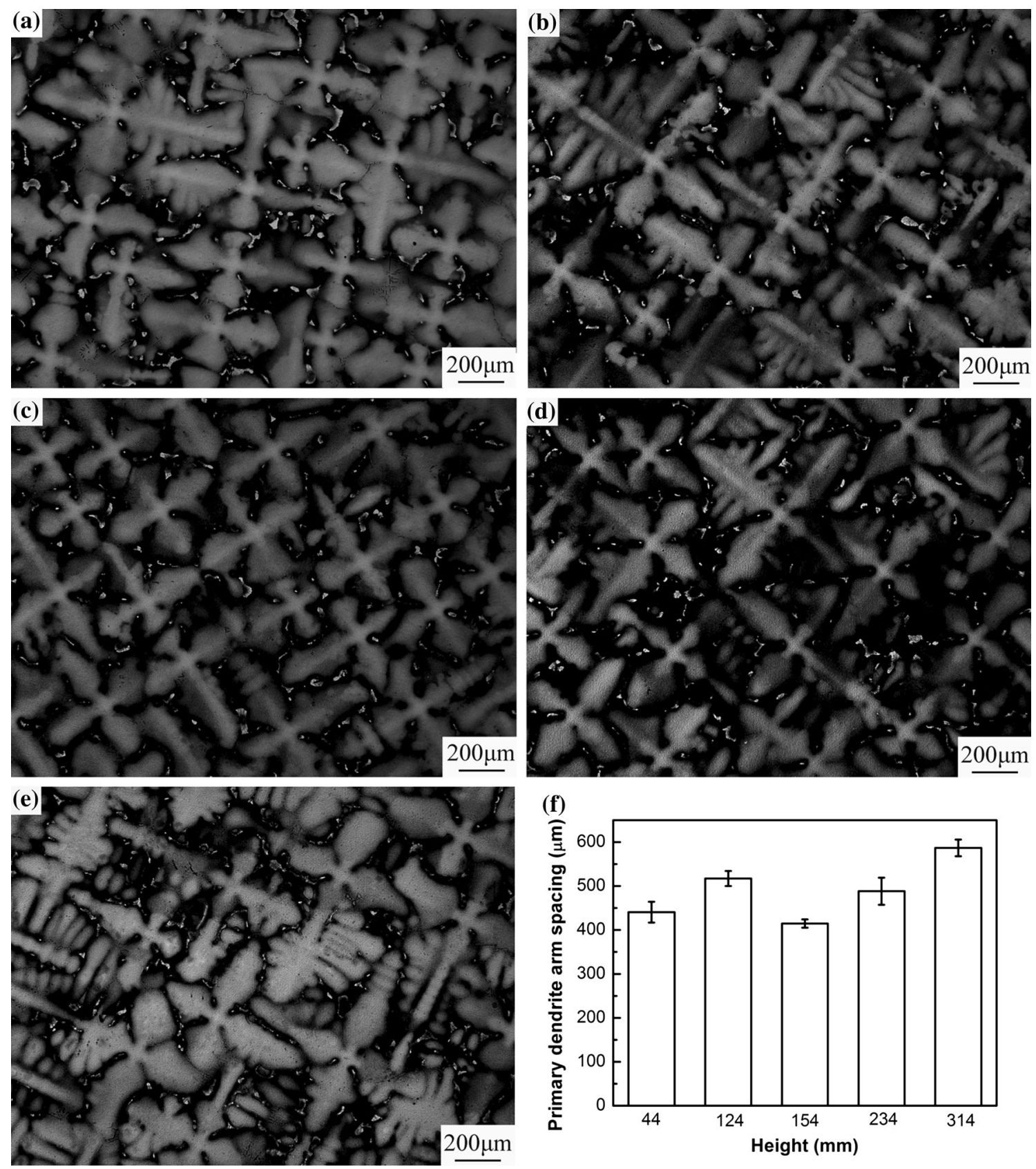

Fig. 2 Transverse dendrite morphologies of samples at different heights in as-cast large-scale single crystal casting DD10 with platform: a $44 \mathrm{~mm}$; b $124 \mathrm{~mm}$; $154 \mathrm{~mm}$; d $234 \mathrm{~mm}$; e $314 \mathrm{~mm}$; f distribution of PDAS in large-scale single crystal casting DD10 with platform

crystal growth direction (from $\mathrm{C}$ to $\mathrm{E}$ ). Figure 3 shows the morphologies of $\gamma / \gamma^{\prime}$ eutectics at different heights in the ascast large-scale SX casting with platform. The daisy-like eutectics are distributed in the interdendritic region, and the eutectic volume fraction is shown in Fig. 3f. The eutectic volume fraction of the samples at position $\mathrm{A}$ is larger than that at position B. After then, the eutectic fraction increases gradually from the position $\mathrm{B}$ to the position $\mathrm{E}$ with the height increase.
Figure 4 shows the dendrite morphologies of the samples at different heights (A-E marked in Fig. 1) in heattreated large-scale SX casting with platform. The dendrite arm cannot be distinguished clearly, and the element microsegregation has been alleviated after heat treatment. The segregation coefficients of major elements in DD10 in the as-cast and heat-treated conditions are listed in Table 2. It is found that the microsegregations of the alloy elements, such as $\mathrm{Ti}$ and $\mathrm{W}$, are reduced significantly after heat treatment. The corresponding $\gamma / \gamma^{\prime}$ eutectic morphologies 

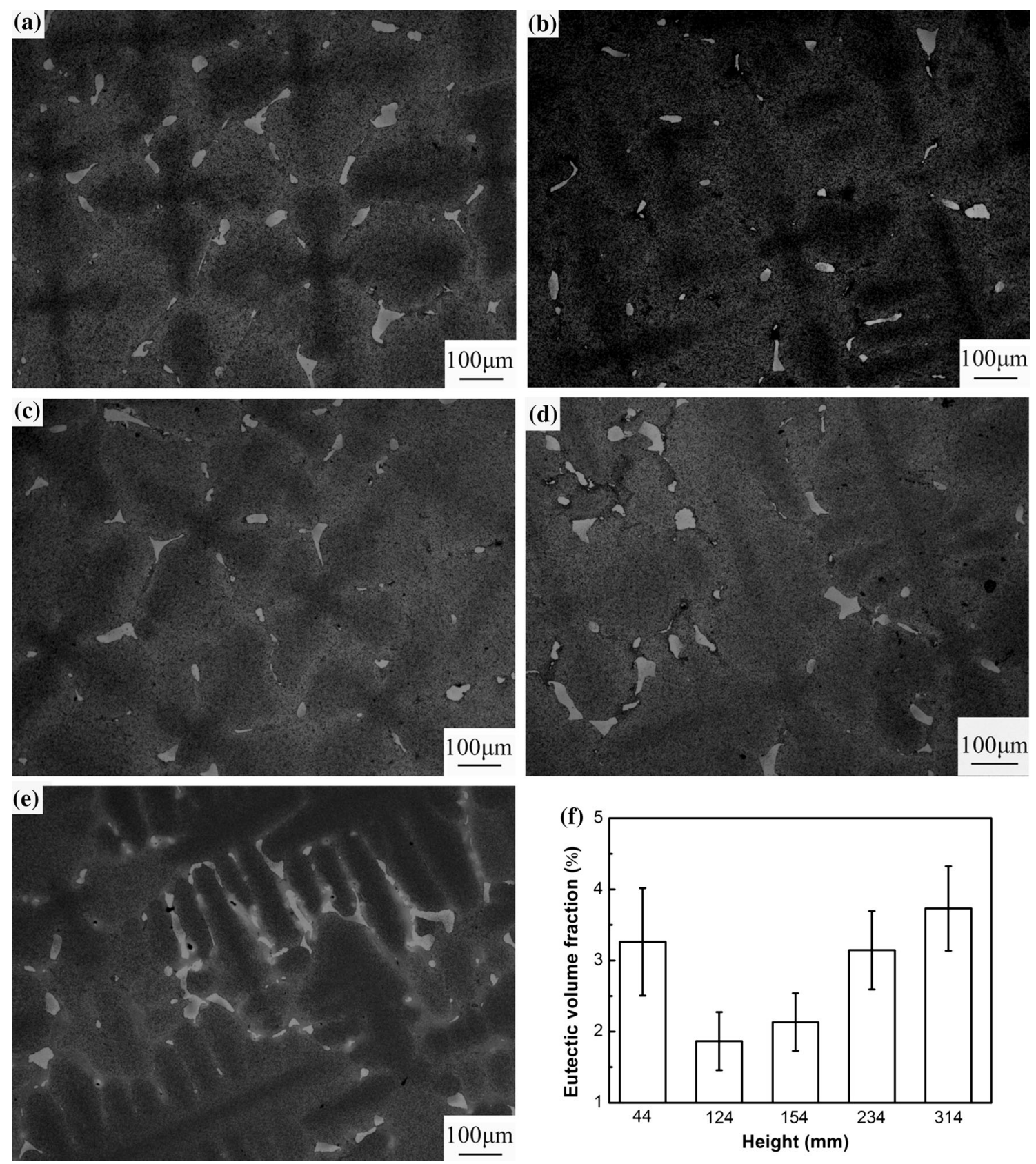

Fig. 3 Transverse $\gamma / \gamma^{\prime}$ eutectic morphologies of samples at different heights in as-cast large-scale single crystal casting DD10 with platform: a $44 \mathrm{~mm}$; b $124 \mathrm{~mm}$; $154 \mathrm{~mm}$; d $234 \mathrm{~mm}$; e $314 \mathrm{~mm}$; f distribution of eutectic volume fraction in as-cast large-scale single crystal casting DD10 with platform

and eutectic volume fraction of the samples at different heights are shown in Fig. 5. Most of the $\gamma / \gamma^{\prime}$ eutectics in the interdendritic region are eliminated after heat treatment. Compared with that in the as-cast condition, the eutectic content of the heat-treated sample is low.

The stress rupture properties of heat-treated large-scale SX casting DD10 with platform in different positions are listed in Table 3. It is found that the rupture lives of the samples at different heights are almost the same at the same direction. At the transverse direction, the rupture lives of the samples $\left(\mathrm{F}, \mathrm{F}^{\prime}\right)$ at different heights are 37.3 and $38.3 \mathrm{~h}$, respectively. At the longitudinal direction, however, the rupture lives of the samples $(\mathrm{H}, \mathrm{I}, \mathrm{J})$ at different heights are 82.6, 81.6 and $82.1 \mathrm{~h}$, respectively. Figure 6 shows the fracture morphologies of the ruptured samples. It is found that the cracks develop along dendrite growth direction in the transverse samples $\left(\mathrm{F}, \mathrm{F}^{\prime}\right)$. However, the typical ductile fractographs with dimple are found in the 

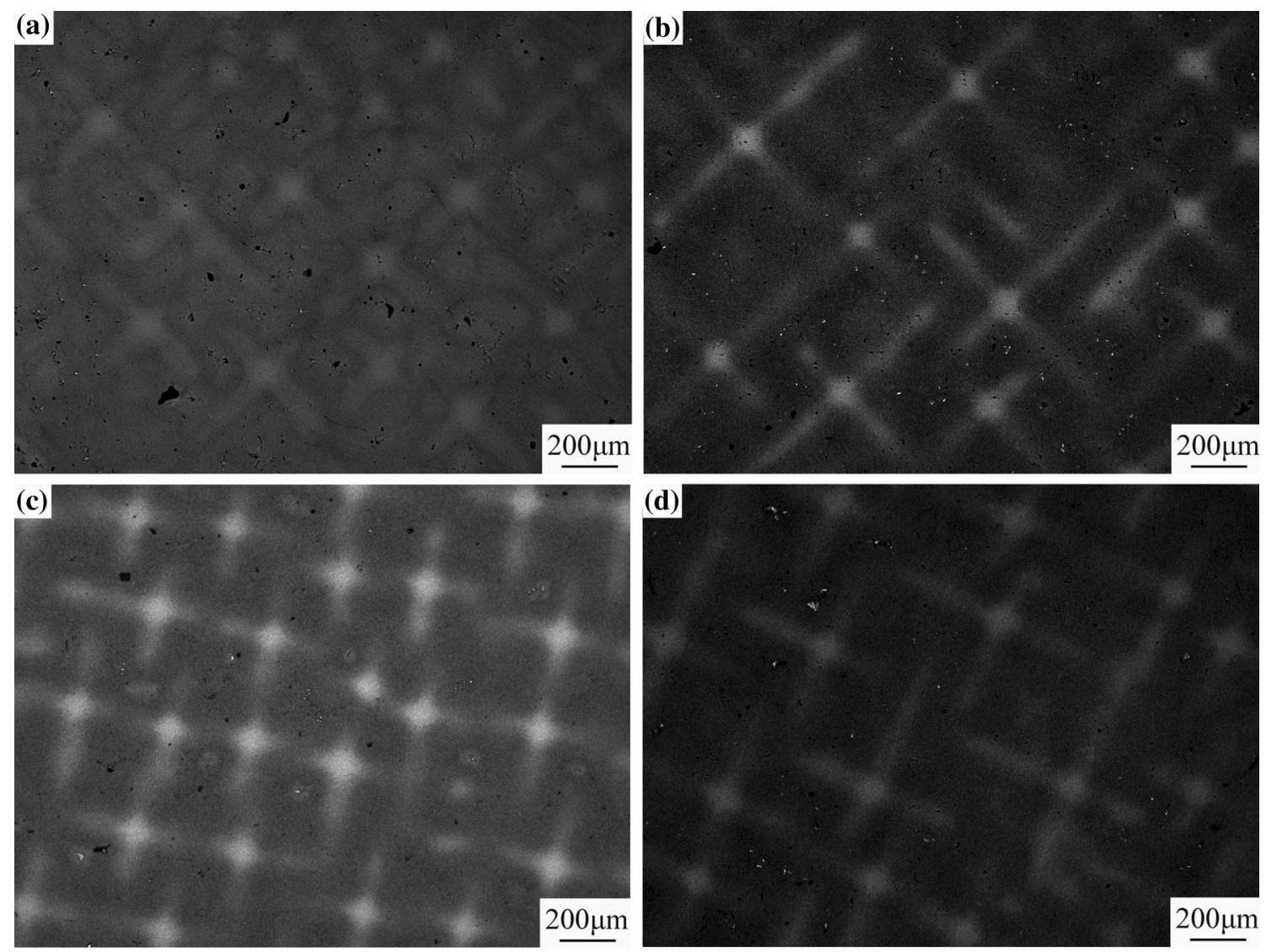

(d)

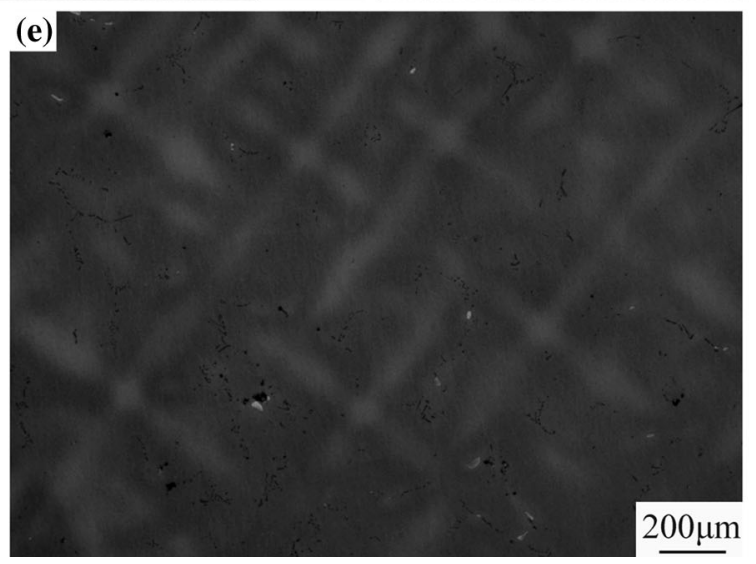

Fig. 4 Transverse dendrite morphologies of samples at different heights in heat-treated large-scale single crystal casting DD10 with platform: a $44 \mathrm{~mm}$; b $124 \mathrm{~mm}$; c $154 \mathrm{~mm}$; d $234 \mathrm{~mm}$; e $314 \mathrm{~mm}$

Table 2 Element segregation coefficients $(k)$ of large-scale single crystal casting DD10 with platform in as-cast and heat-treated conditions

\begin{tabular}{llllllllr}
\hline Sample & Co & Al & Cr & Ti & Ni & Mo & Ta \\
\hline As-cast & 1.050 & 0.984 & 0.979 & $\mathbf{0 . 5 6 9}$ & 1.000 & 0.779 & 0.894 \\
Heat-treated & 1.030 & 0.964 & 1.020 & $\mathbf{0 . 9 6 0}$ & 0.984 & 0.894 & 0.915 & $\mathbf{1 . 7 2 0}$ \\
\hline
\end{tabular}

The bold is to highlight the serious segregation of elements Ti and $\mathrm{W}$

longitudinal samples (H, I, J). As shown in Fig. 7, the main cause of the stress rupture is due to existence of the pores, $\gamma / \gamma^{\prime}$ eutectics, and carbides in the interdendritic region, which results in the crack initiation, the crack propagation, and the ultimate fracture of the casting under applied stress. 

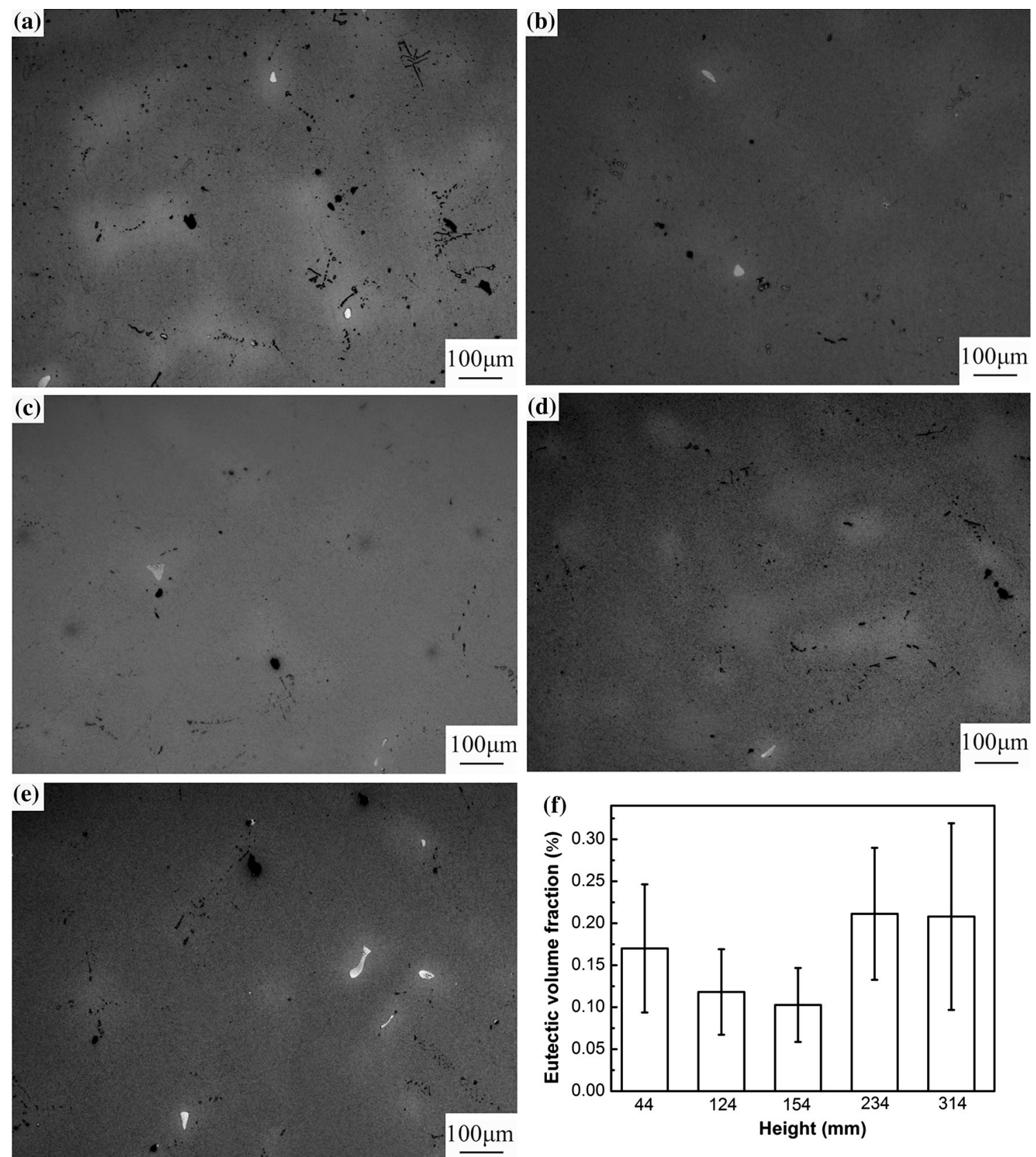

Fig. 5 Transverse $\gamma / \gamma^{\prime}$ eutectic morphologies of samples at different heights in heat-treated large-scale single crystal casting DD10 with platform: a $44 \mathrm{~mm}$; b $124 \mathrm{~mm}$; $154 \mathrm{~mm}$; d $234 \mathrm{~mm}$; $314 \mathrm{~mm}$; distribution of eutectic volume fraction in heat-treated large-scale single crystal casting DD10 with platform

Table 3 Stress rupture properties of large-scale single crystal casting DD10 with platform

\begin{tabular}{ll}
\hline Sample & Rupture life $(\mathrm{h})$ \\
\hline $\mathrm{F}$ & 37.3 \\
$\mathrm{~F}^{\prime}$ & 38.3 \\
$\mathrm{H}$ & 82.6 \\
$\mathrm{I}$ & 81.6 \\
$\mathrm{~J}$ & 82.1 \\
\hline
\end{tabular}

\section{Discussion}

During DS process, the PDAS is inversely proportional to temperature gradient $G$ and solidification rate $V[23,24]$ :

$\mathrm{PDAS} \propto G^{-1 / 2} V^{-1 / 4}$.

The solidification rate may be approximatively equal to the withdrawal rate, which keeps a constant of $3 \mathrm{~mm} / \mathrm{min}$ during the withdrawing process. Due to the fact that the efficiency of heat conduction decreases when the sample is 

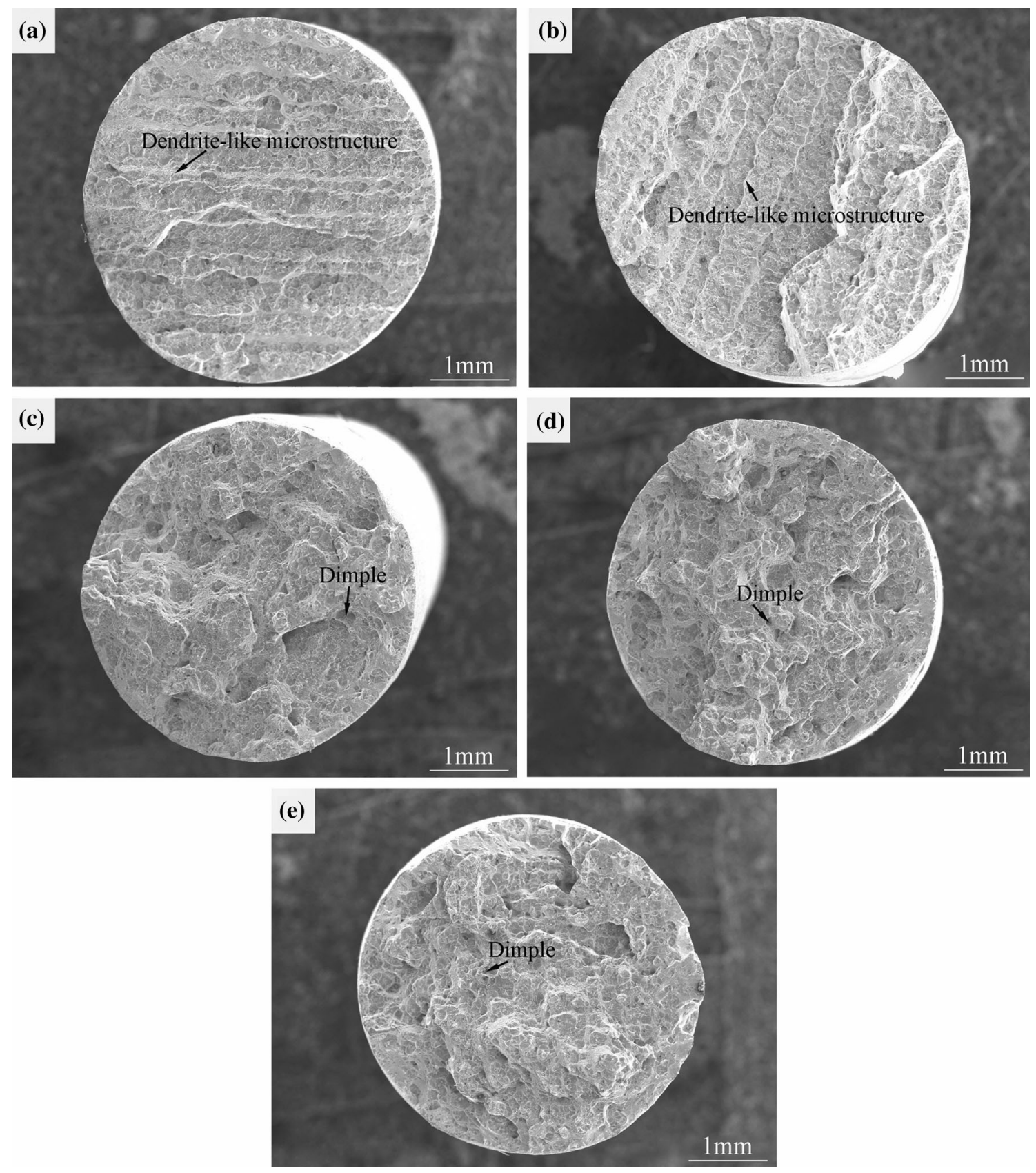

Fig. 6 Fractographies of samples from different positions: F a; F' $\mathbf{b} ; \mathrm{H} \mathbf{c} ; \mathrm{I} \mathbf{d} ; \mathrm{J} \mathbf{e}$

far away from chill copper plate, the temperature gradient reduces gradually with the height increase. Therefore, the PDAS increases slowly. This conclusion is confirmed by the experimental results. A large-scale SX casting without platform was prepared and the corresponding PDAS of the samples at different heights was acquired as shown in Fig. 8. It is found that the PDAS in large-scale SX casting without platform increases gradually with the height increase.

Nevertheless, due to the effect of platform on solidification process, the distribution of PDAS in large-scale SX casting with platform is different. Under the platform from the position A to the position $\mathrm{B}$, due to the effect of the reduction of heat conduction and the existence of platform blocking heat radiation, the temperature gradient decreases, leading to the increase of PDAS at the position B. There is more space for high order dendrites to develop as shown in Fig. 2b. While the solid-liquid interface crossing the platform to the position $\mathrm{C}$, the large-scale platform has been in solidified condition. The efficiency of heat conduction increases due to the sharply increase of the crosssection size of the platform. The temperature gradient at 

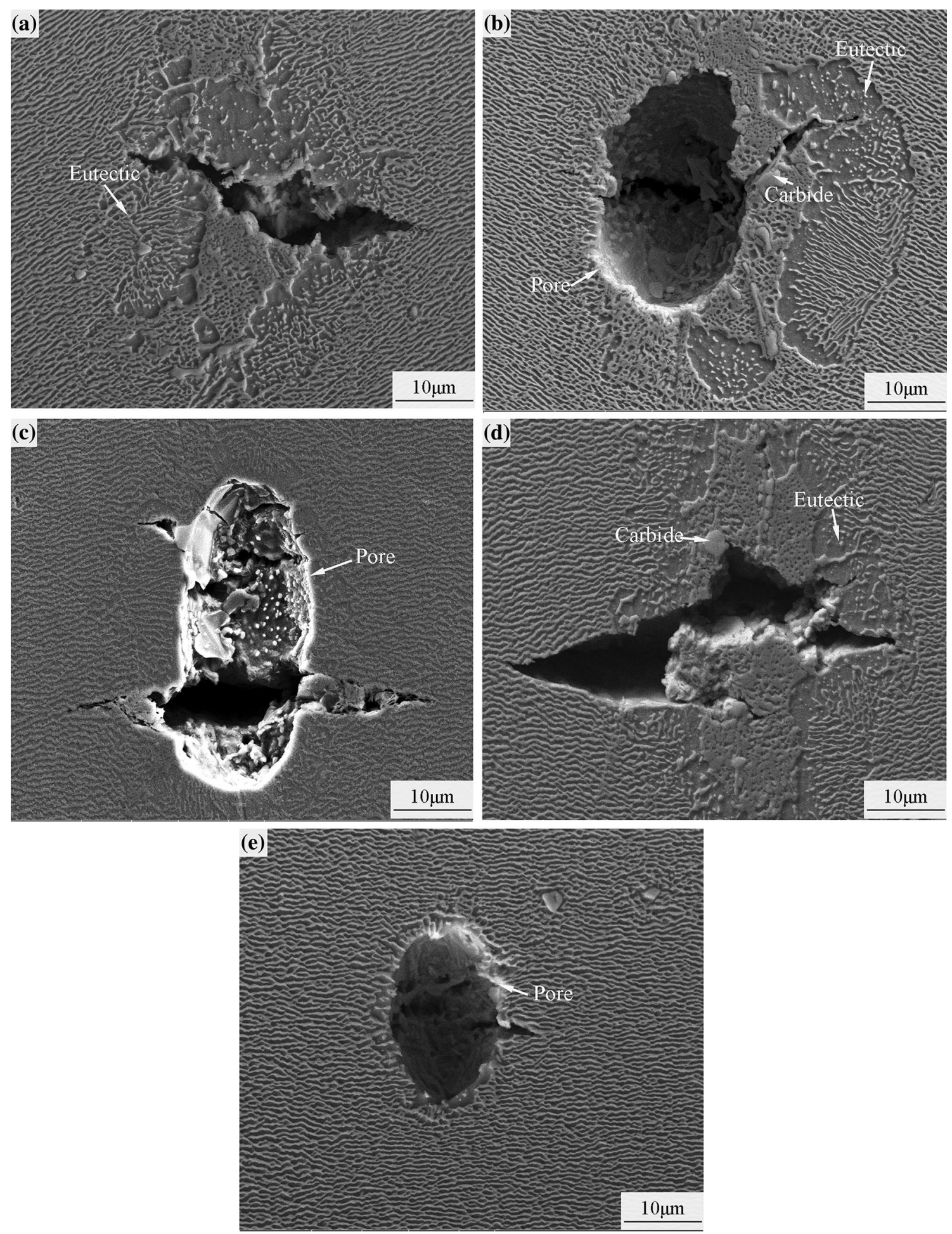

Fig. 7 Crack morphologies of different samples in longitudinal section from stress rupture experiments: a sample F; b sample F'; c sample H; d sample I; e sample J

the position $\mathrm{C}$ is larger than that at the position $\mathrm{B}$, therefore, the PDAS decreases as shown in Fig. 2f. No enough space remains in high order dendrites developing in the interdendritic region, and the dendrites are characterized by a simple cross morphology with few branches as shown in Fig. 2c. After that, the temperature gradient decreases gradually with the height increase, resulting in the increase of PDAS. 

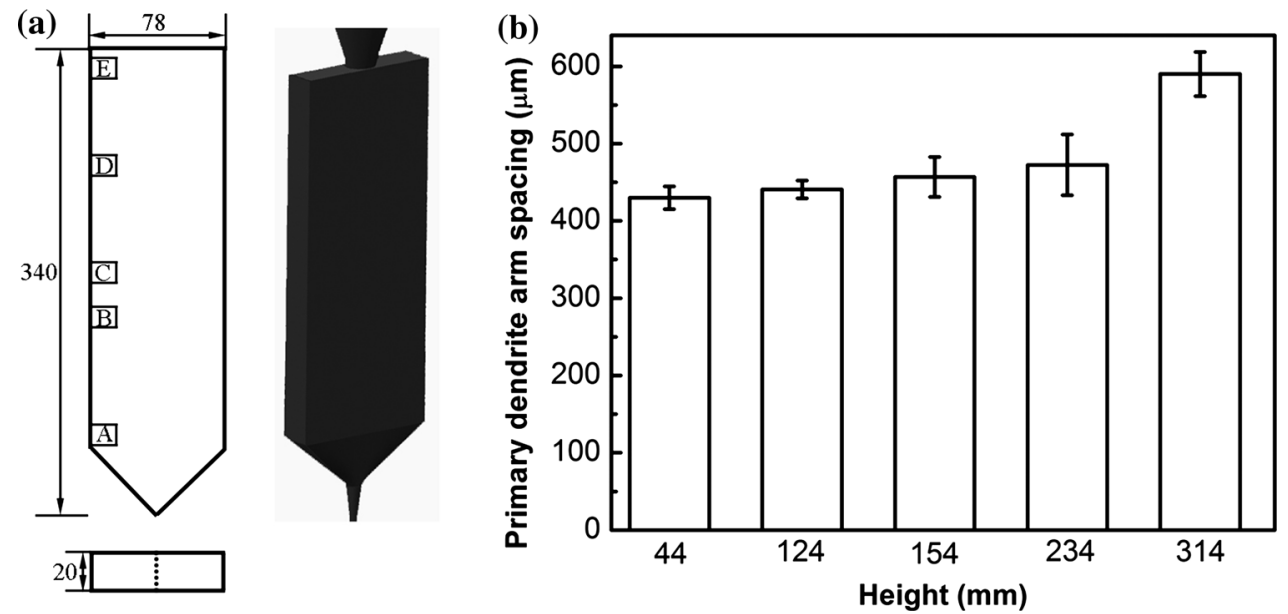

Fig. 8 a Schematic diagram of large-scale single crystal castings without platform (A, B, C, D, and E represent the samples at different heights for microstructural analysis), b Distribution of PDAS at different heights in large-scale single crystal castings without platform

During DS process, the melts solidify in the form of dendrites setting forward at the solid-liquid interface. The elements with high melting points solidify at first, and then they are enriched in dendrite core. While the elements with low melting points, such as $\mathrm{Ti}$ and $\mathrm{Ta}$, are expelled to the liquid nearby, gathering together in the interdendritic region, and finally they solidify in the form of $\gamma / \gamma^{\prime}$ eutectics.

In the as-cast condition, the PDAS of the sample at the position A is smaller than that at the position B. It is well known that fine dendrites are helpful to reduce segregation, which plays a role in decreasing eutectic content $[25,26]$. Due to the increase of PDAS of the sample at the position $\mathrm{B}$, the high order dendrites develop and occupy the interdendritic region as shown in Fig. $3 b$, resulting in the decrease of final solidification zone. In addition, many studies have shown that the solid back diffuse (SBD) occurs and reduces the microsegregation of elements during DS process in nickel-based SX superalloys [27, 28]. Flemings [29] pointed that the effect of PDAS on microsegregation is obviously weaker than that of SBD. However, if the cooling rate increases up to a certain limit, the effect of SBD can be ignored [25]. Position A is close to the chilling copper plate, and the cooling rate is large enough to exceed the critical rate. The effect of SBD at the position $\mathrm{A}$ can be ignored, and the microsegregation of elements is not alleviated. However, at the position B, the cooling rate decreases and the microsegregation is reduced due to the effect of SBD. Therefore, the eutectic volume fraction of the sample at the position B is smaller than that at the position A as shown in Fig. 3f. This is consistent with the conclusion of the literature [29]. While at the position $\mathrm{C}$, the efficiency of heat conduction increases due to the effect of platform. The cooling rate is larger than that at the position $\mathrm{B}$, and the effect of SBD at the position $\mathrm{C}$ is weaker. Therefore, more $\gamma / \gamma^{\prime}$ eutectics are developed and the eutectic volume fraction increases at the position $\mathrm{C}$ as shown in Fig. 3f. With increasing height from the position $\mathrm{D}$ to the position $\mathrm{E}$, the cooling rate decreases gradually, and the solute is redistributed according to Scheil equation [30]:

$C_{\mathrm{S}}^{*}=k C_{\mathrm{L}}^{*}$,

where $C_{\mathrm{S}}^{*}$ is the composition of the solid phase at the interface, $k$ is segregation coefficient, and $C_{\mathrm{L}}^{*}$ is the composition of the liquid phase at the interface. During DS process, the elements with low melting points, such $\mathrm{Ti}$ and $\mathrm{Ta}$, are expelled to the interdendritic region continually. With increasing height, the contents of Ti and Ta increase in large-scale SX casting with platform, which is helpful to the formation of $\gamma / \gamma^{\prime}$ eutectics. In addition, the PDAS increases with the height increase as shown in Fig. 2f, which provides enough space for the final solidification zone. The eutectic volume fraction increases with the height increase from the position D to the position E.

As is known to all, the interdendritic regions near the pores, $\gamma / \gamma^{\prime}$ eutectics, and carbides are the locations where cracks are easy to initiate and propagate. Such microstructural features have a significant effect on stressrupture property. However, most of the $\gamma / \gamma^{\prime}$ eutectics in the interdendritic region are eliminated, and this could lead to eutectic content reduction and the components are distributed uniformly after heat treatment. Therefore, the similar stress rupture properties of the samples at different heights are obtained along with the same direction. 


\section{Conclusions}

1. In large-scale complex SX casting, the PDAS does not increase monotonically with the height increase. When across the platform, the temperature gradient increases due to the effect of the platform, which results in a reduction of PDAS.

2. The eutectic volume fraction is affected by PDAS, solid back diffusion (SBD), and the development of high order dendrites. Under the platform, the eutectic volume fraction decreases with the height increase. However, above the platform, the eutectic volume fraction increases gradually.

3. After heat treatment, most of the $\gamma / \gamma^{\prime}$ eutectics are eliminated and the components are distributed uniformly in large-scale complex SX casting. The similar stress rupture properties of the samples at different heights are obtained.

Acknowledgements This work was supported financially by the National Key Research and Development Program of China (No. 2016YFB0701403) and the National Natural Science Foundation of China (Nos. 51631008 and 51401216).

\section{References}

[1] Z.X. Shi, S.Z. Liu, X.G. Wang, J.R. Li, Acta Metall. Sin. (Engl. Lett.) 30, 614 (2017)

[2] Y.S. Zhao, J. Zhang, Y.S. Luo, D.Z. Tang, Q. Feng, Acta Metall. Sin. 51, 1261 (2015). (in Chinese)

[3] Z.X. Shi, S.Z. Liu, J.R. Li, Rare Metal Mater. Eng. 43, 1138 (2014)

[4] X.F. Yuan, J.X. Song, Y.R. Zheng, Q. Huang, K. Yagi, C.B. Xiao, Q. Feng, Mater. Sci. Eng. A 651, 734 (2016)

[5] R.C. Reed, The Superalloys: Fundamentals and Applications (Cambridge University Press, Cambridge, 2006)

[6] N. D'Souza, M.G. Ardakani, M. McLean, B.A. Shollock, Metall. Mater. Trans. A 31, 2877 (2000)
[7] W. Wang, A. Kermanpur, P.D. Lee, M. McLean, J. Mater. Sci. 38, 4385 (2003)

[8] A. de Bussac, C.A. Gandin, Mater. Sci. Eng. A 237, 35 (1997)

[9] D.X. Ma, Acta Metall. Sin. 51, 1179 (2015). (in Chinese)

[10] J. Zhang, T.W. Huang, L. Liu, H.Z. Fu, Acta Metall. Sin. 51, 1163 (2015). (in Chinese)

[11] J. Yu, Q.Y. Xu, B.C. Liu, J.R. Li, H.L. Yuan, H.P. Jin, J. Mater. Sci. Technol. 24, 369 (2008)

[12] Q.Y. Xu, B.C. Liu, Z.J. Liang, J.R. Li, S.Z. Liu, H.L. Yuan, Mater. Sci. Forum 508, 111 (2006)

[13] X.W. Jiang, H. Li, Foundry Technol. 33, 807 (2012)

[14] X.W. Jiang, H. Li, L.H. Lou, Foundry 63, 883 (2014)

[15] J. Zhang, J. Shen, Y.Z. Lu, L.H. Lou, Acta Metall. Sin. 46, 1322 (2010). (in Chinese)

[16] P. Li, S.S. Li, Y.F. Han, Intermetallics 19, 182 (2011)

[17] J.J. Yu, X.F. Sun, N.R. Zhao, T. Jin, H.R. Guan, Z.Q. Hu, Mater. Sci. Eng. A 460-461, 420 (2007)

[18] F. Cosentino, N. Warnken, J.C. Gebelin, R.C. Reed, J. Mater. Process. Technol. 213, 2350 (2013)

[19] L.K. Ning, Z. Zheng, T. Jin, S. Tang, E.Z. Liu, J. Tong, Y.S. Yu, X.F. Sun, Acta Metall. Sin. 50, 1011 (2014). (in Chinese)

[20] M.S.A. Karunaratne, D.C. Cox, P. Carter, R.C. Reed, in $\mathrm{Su}$ peralloys, ed. by T.M. Pollock, R.D. Kissinger, R.R. Bowman, K.A. Green, M. Mclean, S. Olson, J.J. Schirra (TMS, Warrendale, 2000), p. 263

[21] K. Harris, G.L. Erickson, in Superalloys, ed. by S.D. Antolovich, R.W. Stusrud, R.A. MacKay, D.L. Anton,T. Khan, R.D. Kissinger, D.L. Klarstrom (TMS, Warrendale, 1992), p. 297

[22] A. Szczotok, B. Chmiela, J. Mater. Eng. Perform. 23, 2739 (2014)

[23] M. Vijayakumar, S.N. Tewari, J.E. Lee, P.A. Curreri, Mater. Sci. Eng. A 132, 195 (1991)

[24] W. Kurz, D.J. Fisher, Acta Metall. 29, 11 (1981)

[25] X.Y. Zhang, L. Liu, T.W. Huang, J. Zhang, H.Z. Fu, Rare Metal Mater. Eng. 42, 2547 (2013)

[26] T. Kraft, Y.A. Chang, Metall. Mater. Trans. A 29, 2447 (1998)

[27] S.M. Seo, J.K. Lee, Y.S. Yoo, C.Y. Jo, H. Miyahara, K. Ogi, in Superalloys, ed. by R.C. Reed, K.A. Green, P. Caron, T.P. Gabb, M.G. Fahrmann, E.S. Huron, S.A. Woodard (TMS, Warrendale, 2008), p. 277

[28] A. Thirumalai, A. Akhtar, R.C. Reed, Mater. Sci. Technol. 22, 1 (2006)

[29] M.C. Flemings, Mater. Trans. 46, 895 (2005)

[30] W. Kurz, D.J. Fisher, Fundamentals of Solidification (Trans Tech Publications, Switzerland, 1986), pp. 121-127 